\title{
Review of: "Use of Near-Infrared Imaging using Indocyanine Green Associates with the Lower Incidence of Postoperative Complications After Surgery for Intestinal and Mesenteric Injury"
}

\section{Yi Po Tsang}

Potential competing interests: The author(s) declared that no potential competing interests exist.

1. the number of patients is very small and may not make significant difference on result.

2. the time of recruitment of these patient is too long, in which the good result of icg may be due to improved surgical skills and learning curve rather than due to icg effect.

3. again, the higher complication rate in non icg group may be due to improved surgical techniques in icg era.

4. the author did not mention how to quantify the intensity of icg after injection which may be subject to bias.

5. the author did not mention how to decide the dosage of icg for optimal perfusion to be shown. 